\title{
A cross-sectional survey of night-time symptoms and impact of sleep disturbance on symptoms and health status in patients with COPD
}

This article was published in the following Dove Press journal:

International Journal of COPD

13 February 2017

Number of times this article has been viewed

\author{
Bo Ding' \\ Mark Small ${ }^{2}$ \\ Gina Bergström' \\ Ulf Holmgren' \\ 'Global Medical Affairs, AstraZeneca, \\ Gothenburg, Sweden; ${ }^{2}$ Adelphi Real \\ World, Bollington, UK
}

Background: Sleep disturbance has been termed the forgotten dimension of chronic obstructive pulmonary disease (COPD), but it is clinically important as most patients are affected. This study examined the incremental burden of illness associated with sleep disturbance in COPD, with reference to health status and disease impact, and the degree of concordance between physicians and patients in reporting night-time COPD symptoms.

Methods: Real-world data from $>2,500$ patients with COPD consulting for routine care were derived from respiratory Disease-Specific Programs conducted in Europe, the USA, and China. Night-time COPD symptom burden was assessed from patient and physician perspectives. Patients completed the Jenkins Sleep Evaluation Questionnaire (JSEQ), COPD assessment test (CAT), and EuroQol five-dimension questionnaire (EQ-5D). A regression approach was used to analyze the relationship between sleep disturbance (JSEQ score) and health status (EQ-5D score), adjusting for confounding variables.

Results: Frequency of night-time symptoms was high and was higher when reported by patients than physicians (69.7\% and 65.7\%, respectively). According to the JSEQ, $73.3 \%$ of patients had trouble falling asleep, $75.3 \%$ experienced night-time awakenings, $70.6 \%$ had trouble staying asleep, and $67.7 \%$ woke after a usual amount of sleep feeling worn out. Over half $(52.7 \%)$ of patients received maintenance treatment where night-time symptom relief was stated by the physician as a treatment aim. A one unit increase in JSEQ score was associated with increased CAT score (0.7 units in Europe and the USA; 0.2 units in China). Sleep disturbance was significantly associated with worse health status (odds ratio [OR]: 1.27, 95\% confidence interval [CI]: $1.18,1.36, P<0.001$ for Europe; OR: $1.23,95 \% \mathrm{CI}: 1.12,1.38, P<0.001$ for the USA; and OR: $1.19,95 \% \mathrm{CI}: 1.10,1.28, P<0.001$ for China).

Conclusions: Night-time symptoms and sleep disturbance are common among patients with COPD, and sleep disturbance has a detrimental impact on COPD symptoms and health status.

Keywords: COPD, night-time symptom, sleep disturbance, health status

\section{Introduction}

The process of sleep brings about changes in breathing patterns that further challenge the already suboptimal respiratory system of individuals with chronic obstructive pulmonary disease (COPD). ${ }^{1}$ This often leads to sleep disturbance due to abnormal breathing patterns (sleep-disordered breathing) and reduced sleep quality (diminished slow wave and rapid eye movement [REM] sleep). ${ }^{2,3}$

The reduced air flow and resultant hyperinflation associated with COPD accentuates the hypoventilation normally present during sleep, particularly during the REM phase., ${ }^{2,4}$ This leads to hypoxemia and hypercapnia, both of which have been rrespondence: Bo Ding

Epidemiology (Respiratory), AstraZeneca

Gothenburg, Global Product and

Portfolio Strategy, Global Medical Affairs,

Medical Evidence and Observational

Research, Pepparedsleden I,

SE-43I 83 Mölndal, Sweden

Tel +46317762406

Email bo.ding@astrazeneca.com 
associated with increased frequency of arousals during sleep. ${ }^{2,3}$ Moreover, hypoxemia may lead to cardiovascular (CV) consequences, including cardiac arrhythmias, pulmonary hypertension, and nocturnal death. ${ }^{2}$

Aside from underlying primary sleep disorders, patients with COPD often experience disturbed sleep or poor sleep quality as a result of the emergence of COPD symptoms during the night and/or early morning. ${ }^{2,5,6}$ Dyspnea, chronic cough, and sputum production can be particularly disruptive, and of these, cough appears to be the most frequently reported. ${ }^{5}$ Survey data collected under the 2009 Respiratory Disease-Specific Program (DSP) show high rates (78\%) of night-time disturbance among patients with COPD. ${ }^{7}$

The consequences of sleep disturbance and reduced sleep quality for the health of patients with COPD are wideranging. Compared with unaffected individuals, patients with COPD experience more fatigue and lethargy, higher levels of depression, and have a reduced overall quality of life (QoL), all of which are likely influenced by sleep disturbance. ${ }^{6,8,9}$ Sleep disturbance also leads to small, but potentially important, reductions in forced vital capacity and forced expiratory volume in 1 second $\left(\mathrm{FEV}_{1}\right){ }^{10}$ In addition, the presence of night-time symptoms is associated with more daytime breathlessness, more frequent COPD exacerbations, and greater maintenance therapy use. ${ }^{7}$ Interestingly, the side effects of some COPD medications may include sleep disturbance. ${ }^{11}$ In the most severe cases of COPD, the combination of altered night-time breathing and COPD can lead to respiratory failure. ${ }^{1}$

Despite the potential impact that sleep disturbance can have on patients with COPD, this aspect of the condition is frequently overlooked. In its most recent guidance, the Global Initiative for Chronic Obstructive Lung Disease ${ }^{11}$ mentions sleep disturbance only in the context of monitoring disease progression at follow-up. ${ }^{9}$ This coupled with the current lack of a formal validated definition of night-time symptomatology, which distinguishes night-time symptoms directly related to COPD from the symptoms of disturbed sleep, may serve to perpetuate the ongoing lack of clarity surrounding this topic. ${ }^{9}$

The objectives of this cross-sectional analysis of data derived from a recent respiratory DSP were 1) to examine the proportion of patients with COPD who are affected by sleep disturbance, as quantified by the non-disease-specific Jenkins Sleep Evaluation Questionnaire (JSEQ), a validated measure of sleep quality; ${ }^{12}$ 2) to report the incremental burden of illness associated with sleep disturbance, with reference to health status and disease impact; 3) to examine the degree of concordance between physicians and their patients with respect to reporting on the frequency of nighttime COPD symptoms; and 4) to examine if an association exists between physician-reported treatment of night-time symptoms and the patient-reported sleep disturbances according to the JSEQ.

\section{Methods}

The respiratory DSP is a cross-sectional survey designed to provide impartial observations of real-world clinical practice from a physician and matched patient perspective. ${ }^{13}$ The survey can be viewed as four discrete stages. In Stage A, primary care and specialist physicians are screened and recruited with a view to obtaining nationally representative samples. Individual face-to-face interviews then take place with the physician (Stage B) who completes patient record forms for the next five consecutive patients with COPD or asthma-COPD overlap syndrome (ACOS) recording clinical and treatment characteristics (Stage C). In the final Stage D, patients fill out a self-completion record, with no influence or input from a health care professional. The respiratory DSP was conducted in Q4 2013 in France, Germany, Italy, Spain, the UK, and the USA and in Q4 2010 in China (from hospital-based physicians only). The respiratory DSP adhered to market research guidelines and codes of conduct; therefore, ethics approval was not necessary to obtain and was not sought. All data were anonymized and aggregated prior to receipt by Adelphi Real World.

\section{Survey population}

\section{Patients and physicians}

The patient population comprised patients aged $>40$ years with physician-confirmed airflow obstruction and a diagnosis of COPD, consulting for routine care. This included patients with emphysema and chronic bronchitis and those with a concomitant diagnosis of asthma (ACOS). Physicians were eligible for participation in the study if they became medically qualified between 5 and 35 years ago and were responsible for the treatment of patients with asthma and those with COPD.

\section{Variables}

\section{General and COPD-related variables}

Outcome variables were recorded directly by the patient or physician or were derived from the physician- or patientcompleted questionnaires (which included the full 8-item COPD Assessment Test [CAT], GlaxoSmithKline, Brentford, UK; mean CAT score; and CAT score range [0-9, 10-19, 20-29, and 30-40]). Descriptive variables recorded by the physician included age, gender, smoking status and history, 
comorbidities, most recent $\mathrm{FEV}_{1}$ (\% predicted), number of exacerbations in the last 12 months, and currently prescribed medications for COPD.

Physicians were asked whether "improvement of nighttime symptom relief" and/or "improvement of daytime symptom relief" were key reasons for the selection of COPD medication. Both physicians and patients were asked to provide information pertaining to the frequency of night-time COPD symptoms during the past 4 weeks.

\section{Night-time symptoms}

Night-time symptom frequency was measured by the patient and the physician. Both were asked, "During the past 4 weeks, how often have you/has this patient had symptoms during the night?" There were five possible answers: not at all, less than once a week, once or twice a week, 3 to 6 times per week, or every day.

\section{Sleep disturbance}

Sleep disturbance was quantified using the JSEQ, which was completed by the patient. ${ }^{12}$ Questions related to the ease with which patients fell asleep and to the number of night-time or early awakenings they typically experienced. Feelings of persistent tiredness or exhaustion following their usual amount of sleep were also reported.

\section{Health status and functional impairment}

The health status of the patient was determined from a physician-completed three-level version of the EuroQol five-dimension questionnaire (EQ-5D-3L). ${ }^{14}$ The health dimensions of mobility, self-care, usual activities, pain/ discomfort, and anxiety/depression were rated according to three response options (no problems, some problems, and extreme problems). Patients also provided information on their psychological or functional impairment. They were asked whether they had ever experienced selected emotions as a result of their COPD (constant lack of energy, tiredness through lack of sleep, sickness, anxiety, feelings of sadness/ depression, difficulty expressing feelings, embarrassment about their condition, or feelings of irritability).

\section{Statistical analyses}

Patient- and physician-reported general and COPD-related variables, including night-time symptom burden, were expressed using descriptive statistics. Across all analyses, data for patients from France, Germany, Italy, Spain, and the UK were grouped collectively as "Europe". All analyses were performed using Stata 13.1 (StataCorp LP. Stata Statistical Software: Release 13. 2013).

\section{Sleep disturbance}

The proportion of patients with sleep disturbances during the past month, assessed using the JSEQ, was evaluated in terms of overall mean score and individual item scores for 1) trouble falling asleep, 2) trouble staying asleep, 3) waking up several times per night, and 4) waking up feeling tired and worn out after a usual amount of sleep. The response alternatives were not at all (0), 1-3 days (1), 4-7 days (2), 8-14 days (3), 15-21 days (4), and 22-31 days (5). In the absence of a validated threshold JSEQ score with which to classify "high" or "low" sleep disturbance, we used the raw continuous form of the scale, ranging from no sleep disturbance (score of 0 ) to high sleep disturbance (score of 20 indicating between 22 and 28 days of disturbed sleep for all four items in the JSEQ).

Logistic and linear regression modeling was used to quantify the relationship between JSEQ score and health status, as measured by the EQ-5D-3L, whilst adjusting for confounding variables (including age, gender, physicianconfirmed diagnosis of depression, anxiety, sleep apnea, serious CV conditions, and number of severe exacerbations in the last 12 months requiring an emergency department visit or hospitalization [as a proxy for severity]).

\section{Health status}

EQ-5D-3L responses were used to calculate a utility score, which ranged between 0 (worst health imaginable) and 1 (best health imaginable). Given that the bimodal distribution of the EQ-5D does not lend itself well to a single regression, a two-part modeling process was used. Logistic regression was first used to determine whether patients had perfect health, using the JSEQ and the confounding variables listed above as predictor variables. Standard ordinary least squares regression was then used for the patients in poor health using the same set of predictor variables. Perfect health was defined as an EQ-5D-3L score of 1 and non-perfect health $<1$. For the logistic regression, an odds ratio $>1$ represented the change in odds of a non-perfect health for a unit increase in JSEQ score. For the linear regression of JSEQ score with EQ-5D, a positive coefficient was associated with a patient with worse health status (lower EQ-5D score). A higher/lower value of the coefficient indicated a greater effect of the variable.

\section{CAT score}

The distribution of CAT scores allowed for analysis according to an ordinary least squares regression model. The predictor variables consisted of the JSEQ score and the confounding variables, as stated above. To eliminate any potential impact of the CAT sleep component on the overall measurement of 
health status, a 7-item version of the CAT was implemented, from which the sleep component was excluded. A positive coefficient was associated with a higher CAT score.

\section{Concordance between physician- and patient- reported night-time COPD symptoms}

Weighted kappa statistics ${ }^{15}$ were used to measure the concordance of reporting of night-time COPD symptoms by physicians and patients.

\section{Results}

\section{Study population}

Of the total patient sample from the respiratory DSP survey who had data collected within the observation period $(\mathrm{N}=4,143), 2,504$ patients were eligible for inclusion in the study population (Tables 1 and 2). The majority (65.1\%) of the study population were males and the mean (standard deviation [SD]) age was 64.6 (10.7) years. A high proportion $(40.1 \%)$ of patients in the cohort from China had never smoked, in contrast to the patient cohorts from Europe and the USA (in which "never smoked" rates were $6.3 \%$ and $4.9 \%$, respectively; Table 2 ).

\section{Clinical characteristics and COPD symptom score}

For the population as a whole, the most recent mean (SD) post-bronchodilator $\mathrm{FEV}_{1}$ was $62.9 \%$ (17.8) of the predicted value (Table 2 ), in the range classified as moderate airflow limitation $\left(50 \% \leq \mathrm{FEV}_{1}<80 \%\right.$ predicted $) .{ }^{11}$ The mean (SD) number of exacerbations in the last 12 months was 1.4 (2.3). Common non-CV-related comorbidities including diabetes, arthritis, and anxiety were reported in $15.1 \%, 13.8 \%$, and $12.0 \%$ of patients, respectively. Sleep apnea was reported in $5.1 \%$ of the study population. Of CVrelated comorbidities, arterial hypertension was the most common and was reported in $55.2 \%$ of patients, whereas

Table I Study population by country

\begin{tabular}{ll}
\hline & $\begin{array}{l}\text { Total } \\
\text { COPD, } \mathbf{n}(\%)\end{array}$ \\
\hline France & $314(12.5)$ \\
Germany & $402(16.1)$ \\
Italy & $180(7.2)$ \\
Spain & $336(13.4)$ \\
UK & $126(5.0)$ \\
USA & $471(18.8)$ \\
China & $675(27.0)$ \\
Total & $2,504(100)$ \\
\hline
\end{tabular}

Abbreviation: COPD, chronic obstructive pulmonary disease. elevated cholesterol/hyperlipidemia was reported in $26.4 \%$ of patients. Serious CV conditions (a collective term encompassing angina, cardiac arrhythmia, cerebrovascular disease, and/or stroke; coagulated blood-clotting disorder; myocardial infarction; thrombosis; congestive heart failure; peripheral vascular disease; and coronary artery disease) were reported in $28.5 \%$ of patients.

COPD symptom scores were generally higher among patients in the cohort from China (mean [SD] CAT score 24.8 [6.1]) compared with the cohorts from Europe (20.5 [8.4]) and the USA (20.4 [8.6]; Table 3). Similarly, China had the greatest proportion of patients with a mean CAT score of $\geq 10$ (98.5\%) in comparison with $88.9 \%$ for Europe and $86.5 \%$ for the USA. For the entire study population, $91.2 \%$ of patients had a mean CAT score of $\geq 10$ and $64.6 \%$ of patients had a mean CAT score of $\geq 20$ (Table 3 ).

\section{Night-time symptoms}

Surveyed physicians in Europe and the USA reported that $65.7 \%$ of patients had night-time symptoms during the last 4 weeks, with $23.2 \%$ of patients experiencing night-time symptoms on a weekly or twice weekly basis. Physicians reported that $8.2 \%$ of their patients had night-time symptoms on a daily basis (Figure 1A). Corresponding patient-reported rates were generally higher, as $69.7 \%$ said that they experienced night-time symptoms during the last 4 weeks, $25.5 \%$ of patients reported night-time symptoms occurring at least once or twice per week, and 9.2\% said that they experienced night-time symptoms every day (Figure 1B). Rates of agreement between physician and patient reports of the frequency of night-time symptoms were $88.9 \%$ and $85.6 \%(P<0.001$ for both) for Europe and the USA (weighted kappa scores of 0.68 and 0.60 , respectively). This indicated borderline moderate-substantial concordance between physicians and patients as sources of information. The mean (SD) JSEQ score for the entire study population was 6.1 (4.8). Night-time awakening was the most common characteristic of sleep disturbance, which was reported as occurring at least 1-3 times in the last 28 days in $75.3 \%$ of patients (Table 4 ).

\section{Health status and psychological or functional impairment}

The overall mean (SD) health status for the entire population, in terms of EQ-5D-3L score, was 0.7 (0.3). Patients in the USA and China showed a marginally better health status (0.8) compared with those in Europe (0.7; Table 3). Tiredness through lack of sleep was reported in $36.5 \%$ of the population as a whole, with more than half $(58.3 \%)$ of 
Table 2 Patient demographics and clinical characteristics

\begin{tabular}{|c|c|c|c|c|}
\hline & Overall $(n=2,504)$ & $5 E U(n=I, 358)$ & USA $(n=47 I)$ & China $(n=675)$ \\
\hline \multicolumn{5}{|l|}{ Age (years) } \\
\hline Number of missing observations & 0 & 0 & 0 & 0 \\
\hline Mean $(S D)$ & $64.6(10.7)$ & $65.3(10.4)$ & $66.6(10.0)$ & $62.0(11.4)$ \\
\hline \multicolumn{5}{|l|}{ Sex, n (\%) } \\
\hline Number of missing observations & 0 & 0 & 0 & 0 \\
\hline Male & I,629 (65.1) & $959(70.6)$ & $260(55.2)$ & $410(60.7)$ \\
\hline \multicolumn{5}{|l|}{ Race, n (\%) } \\
\hline Number of missing observations & $4(0.2)$ & $4(0.3)$ & 0 & 0 \\
\hline Caucasian & I,69I (67.6) & $1,290(95.3)$ & $40 \mathrm{I}(85.1)$ & 0 \\
\hline African American & $42(1.7)$ & 0 & $42(8.9)$ & 0 \\
\hline Hispanic & $52(2.1)$ & $33(2.4)$ & $19(4.0)$ & 0 \\
\hline Asian - Indian subcontinent & $8(0.3)$ & $5(0.4)$ & $3(0.6)$ & 0 \\
\hline Asian - other & $10(0.4)$ & $4(0.3)$ & $6(1.3)$ & 0 \\
\hline Chinese & $675(27.0)$ & 0 & 0 & $675(100.0)$ \\
\hline Other & $22(0.9)$ & $22(1.6)$ & 0 & 0 \\
\hline \multicolumn{5}{|l|}{ BMI $\left(\mathbf{k g} / \mathbf{m}^{2}\right)$} \\
\hline Number of missing observations (\%) & $102(4.1)$ & $71(5.2)$ & $31(6.6)$ & 0 \\
\hline Mean (SD) & $25.7(4.6)$ & $26.1(4.4)$ & $27.8(6.0)$ & $23.5(2.9)$ \\
\hline \multicolumn{5}{|l|}{ Employment status, n (\%) } \\
\hline Number of missing observations & $81(3.2)$ & $46(3.4)$ & $32(6.8)$ & $3(0.4)$ \\
\hline Employed & $609(25.1)$ & $318(24.2)$ & $138(3 \mid .4)$ & I 53 (22.8) \\
\hline Retired & $1,429(59.0)$ & $767(58.5)$ & $222(50.6)$ & $440(65.5)$ \\
\hline Homemaker & $130(5.4)$ & $74(5.6)$ & $27(6.2)$ & $29(4.3)$ \\
\hline Unemployed & $180(7.4)$ & 104 (7.9) & $26(5.9)$ & $50(7.4)$ \\
\hline On long-term disability & $75(3.1)$ & $49(3.7)$ & $26(5.9)$ & 0 \\
\hline \multicolumn{5}{|l|}{ Smoking status, n (\%) } \\
\hline Number of missing observations & $13(0.5)$ & I $(0.1)$ & $\mathrm{I}(0.2)$ & II (I.6) \\
\hline Current smoker & $736(29.6)$ & $472(34.8)$ & $150(31.9)$ & $114(17.2)$ \\
\hline Ex-smoker & $\mathrm{I}, 38 \mathrm{I}(55.4)$ & $800(59.0)$ & $297(63.2)$ & $284(42.8)$ \\
\hline Never smoked & $374(15.0)$ & $85(6.3)$ & $23(4.9)$ & $266(40.1)$ \\
\hline \multicolumn{5}{|l|}{ Pack-years (grouped), n (\%) } \\
\hline Number of missing observations & $93(3.7)$ & $52(3.8)$ & $29(6.2)$ & $12(1.8)$ \\
\hline$<10$ & $515(21.4)$ & $155(11.9)$ & $48(10.9)$ & $312(47.1)$ \\
\hline$\geq 10$ & I,896 (78.6) & $\mathrm{I}, 15 \mathrm{I}(88.1)$ & $394(89.1)$ & $35 \mathrm{I}(52.9)$ \\
\hline \multicolumn{5}{|c|}{ Proportion of patients with ACOS, n (\%) } \\
\hline Number of missing observations & $9(0.4)$ & $8(0.6)$ & $\mathrm{I}(0.2)$ & 0 \\
\hline No asthma diagnosis & $2,200(88.2)$ & $\mathrm{I}, 28 \mathrm{I}(94.9)$ & $432(91.9)$ & $487(72.2)$ \\
\hline Physician-confirmed ACOS & $295(11.8)$ & $69(5.1)$ & $38(8.1)$ & $188(27.9)$ \\
\hline \multicolumn{5}{|c|}{ Most recent FEV, test score (post-bronchodilator), \% predicted } \\
\hline Number of missing observations (\%) & $\mathrm{I}, 496(59.7)$ & $718(52.9)$ & $284(60.3)$ & $494(73.2)$ \\
\hline Mean (SD) & $62.9(17.8)$ & $64.6(17.9)$ & $62.7(17.3)$ & $57.2(16.5)$ \\
\hline \multicolumn{5}{|c|}{ Number of COPD exacerbations in the last 12 months } \\
\hline Number of missing observations (\%) & $7(0.3)$ & $2(0.1)$ & $\mathrm{I}(0.2)$ & $4(0.6)$ \\
\hline Mean (SD) & I.4 (2.3) & I.5 (I.8) & I.3 (I.7) & $1.4(3.2)$ \\
\hline
\end{tabular}

Abbreviations: ACOS, asthma-COPD overlap syndrome; BMI, body mass index; COPD, chronic obstructive pulmonary disease; EU, European Union; FEV , forced expiratory volume in I second; SD, standard deviation.

patients surveyed in China reporting such an impairment (Table 3 ). A constant lack of energy was reported by $42.7 \%$ of patients overall.

Logistic regression analysis of patients in Europe revealed a significant association between increased sleep disturbance, as measured using the JSEQ, and worse health status (EQ-5D-3L score: $<1$; OR: $1.27,95 \%$ CI: 1.18, 1.36, $P<0.001)$. Similar associations were also found for patients surveyed in the USA
(OR: $1.23,95 \%$ CI: 1.12, 1.38, $P<0.001)$ and China (OR 1.19, 95\% CI: 1.10, 1.28, $P<0.001$; Table 5).

\section{Symptoms}

Linear regression analysis revealed a significant association between JSEQ score and the adapted 7-item CAT score, showing that increasing sleep disturbances had a significant impact on COPD symptoms (Europe, coefficient: 0.695, $P<0.001$; 
Table 3 Patient-reported CAT score, health status, and psychological or functional impairment

\begin{tabular}{|c|c|c|c|c|}
\hline & Overall $(n=2,504)$ & $5 E U(n=I, 358)$ & USA $(n=47 I)$ & China $(n=675)$ \\
\hline \multicolumn{5}{|l|}{ 8-item CAT score } \\
\hline Number of missing observations (\%) & $136(5.4)$ & $93(6.8)$ & $42(8.9)$ & $\mathrm{I}(0.1)$ \\
\hline Mean (SD) & $21.7(8.1)$ & $20.5(8.4)$ & $20.4(8.6)$ & $24.8(6.1)$ \\
\hline \multicolumn{5}{|l|}{ 8-item CAT score (grouped), n (\%) } \\
\hline Number of missing observations & $136(5.4)$ & $93(6.8)$ & $42(8.9)$ & $\mathrm{I}(0 . \mathrm{I})$ \\
\hline $0-9$ & $208(8.8)$ & $140(11.1)$ & $58(13.5)$ & $10(1.5)$ \\
\hline $10-19$ & $631(26.7)$ & $409(32.3)$ & $120(28.0)$ & $102(15.1)$ \\
\hline $20-29$ & $1,126(47.6)$ & $525(4 \mid .5)$ & $185(43.1)$ & $416(61.7)$ \\
\hline $30-40$ & $403(17.0)$ & $191(15.1)$ & $66(15.4)$ & $146(21.7)$ \\
\hline \multicolumn{5}{|l|}{ EQ-5D-3L index score } \\
\hline Number of missing observations (\%) & $85(3.4)$ & $47(3.5)$ & $38(8.1)$ & 0 \\
\hline Mean (SD) & $0.7(0.3)$ & $0.7(0.3)$ & $0.8(0.2)$ & $0.8(0.3)$ \\
\hline \multicolumn{5}{|c|}{ Psychological or functional impairment, n (\%) } \\
\hline Number of missing observations & $5 I(2.0)$ & $30(2.2)$ & $20(4.2)$ & $\mathrm{I}(0.1)$ \\
\hline Constant lack of energy & $\mathrm{I}, 047(42.7)$ & $484(36.5)$ & $170(37.7)$ & $393(58.3)$ \\
\hline Tiredness through lack of sleep & $896(36.5)$ & $377(28.4)$ & $126(27.9)$ & $393(58.3)$ \\
\hline Sickness & $343(14.0)$ & $35(2.6)$ & $33(7.3)$ & $275(40.8)$ \\
\hline Nervousness or anxiety & $668(27.2)$ & $299(22.5)$ & $109(24.2)$ & $260(38.6)$ \\
\hline Feelings of sadness or depression & $335(13.7)$ & $186(14.0)$ & $59(13.1)$ & $90(13.4)$ \\
\hline Difficulty expressing your feelings & $177(7.2)$ & $86(6.5)$ & $27(6.0)$ & $64(9.5)$ \\
\hline Embarrassment about your condition & $336(13.7)$ & $194(14.6)$ & $61(13.5)$ & $81(12.0)$ \\
\hline Scared and worried about your condition & $578(23.6)$ & $306(23.0)$ & $112(24.8)$ & $160(23.7)$ \\
\hline Feelings of irritability & $442(18.0)$ & $259(19.5)$ & $85(18.9)$ & $98(14.5)$ \\
\hline None of them & $515(21.0)$ & $348(26.2)$ & $130(28.8)$ & $37(5.5)$ \\
\hline
\end{tabular}

Abbreviations: CAT, COPD assessment test; COPD, chronic obstructive pulmonary disease; EQ-5D-3L, EuroQol five-dimension questionnaire; EU, European Union; $\mathrm{SD}$, standard deviation.

USA, coefficient: $0.725, P<0.001$; China, coefficient: $0.224, P=0.001$; Table 5). Therefore, for patients surveyed in Europe and the USA, an increase of 1 in JSEQ score was associated with a 0.7 increase in the CAT score, indicating a greater effect of sleep disturbance on the CAT score than was observed in patients surveyed in China.

A

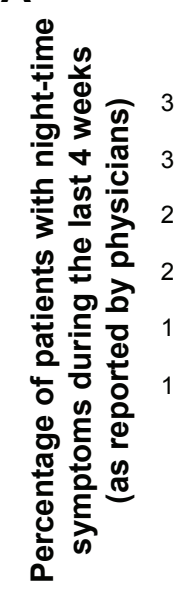

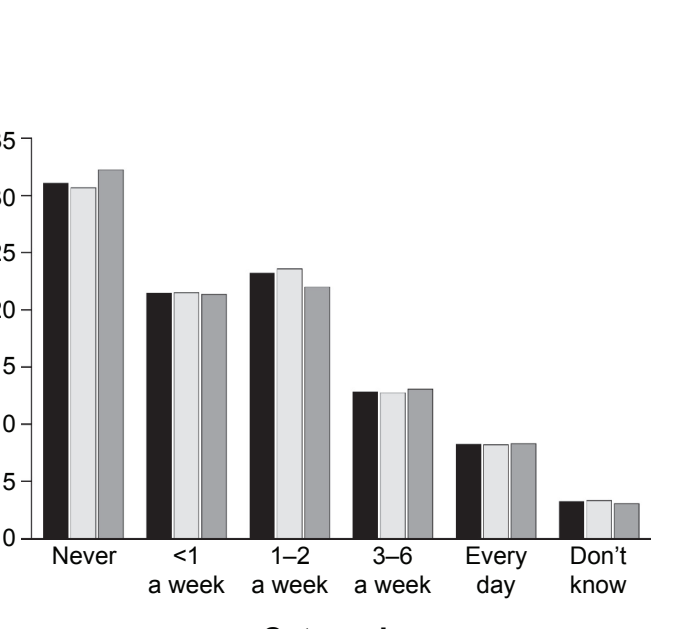

Categories

\section{Current treatment of COPD and reason for medication prescription}

In Europe and the USA, the physician responsible for treatment decisions was a pulmonologist or equivalent for $56.9 \%$ and $53.7 \%$ of patients respectively. All patients surveyed in China received care from a hospital-based respiratory

B

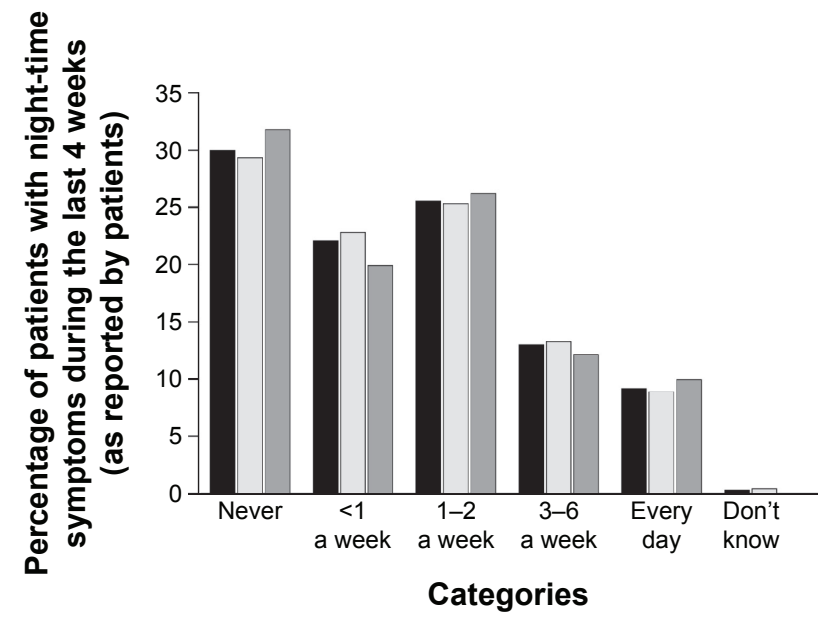

Overall (n=1,829) $\square 5$ EU (n=1,358) $\square$ USA (n=471)

Figure I Frequency of night-time symptoms reported in Europe and the USA during the last 4 weeks by $(\mathbf{A})$ physicians and (B) patients. Abbreviation: EU, European Union. 
Table 4 Jenkins Sleep Evaluation Questionnaire (JSEQ) findings

\begin{tabular}{|c|c|c|c|c|}
\hline & Overall $(n=2,504)$ & $5 E U(n=I, 358)$ & USA $(n=47 I)$ & China $(n=675)$ \\
\hline \multicolumn{5}{|c|}{ JSEQ score (0-20) } \\
\hline Mean (SD) & $6.1(4.8)$ & $6.1(5.0)$ & $5.4(4.7)$ & $6.3(4.6)$ \\
\hline \multicolumn{5}{|c|}{ How often in the past 4 weeks did you: have trouble falling asleep? $n(\%)$} \\
\hline (0) Not at all & $669(26.7)$ & $386(28.4)$ & $17 \mid(36.3)$ & $112(16.6)$ \\
\hline (I) $1-3$ days & $768(30.7)$ & $427(31.4)$ & $134(28.5)$ & $207(30.7)$ \\
\hline (2) 4-7 days & $55 \mathrm{I}(22.0)$ & $293(21.6)$ & $90(19.1)$ & $168(24.9)$ \\
\hline (3) $8-14$ days & $264(10.5)$ & $14 \mid(10.4)$ & $39(8.3)$ & $84(12.4)$ \\
\hline (4) $|5-2|$ days & $142(5.7)$ & $65(4.8)$ & $26(5.5)$ & $51(7.6)$ \\
\hline (5) $22-28$ days & $110(4.4)$ & $46(3.4)$ & II (2.3) & $53(7.9)$ \\
\hline Mean (SD) score & $1.5(1.4)$ & $1.4(1.3)$ & I.3 (I.3) & $1.9(1.5)$ \\
\hline \multicolumn{5}{|c|}{ How often in the past 4 weeks did you: wake up several times per night? n (\%) } \\
\hline (0) Not at all & $618(24.7)$ & $343(25.3)$ & $136(28.9)$ & $139(20.6)$ \\
\hline (I) I-3 days & $772(30.8)$ & $424(31.2)$ & $146(31.0)$ & $202(29.9)$ \\
\hline (2) 4-7 days & $524(20.9)$ & $273(20.1)$ & $103(21.9)$ & $148(21.9)$ \\
\hline (3) $8-14$ days & 297 (11.9) & $162(11.9)$ & $46(9.8)$ & $89(13.2)$ \\
\hline (4) $|5-2|$ days & $159(6.4)$ & $87(6.4)$ & $25(5.3)$ & $47(7.0)$ \\
\hline (5) $22-28$ days & $134(5.4)$ & $69(5.1)$ & $15(3.2)$ & $50(7.4)$ \\
\hline Mean (SD) score & $1.6(1.4)$ & $1.6(1.4)$ & $1.4(1.3)$ & $1.8(1.5)$ \\
\hline \multicolumn{5}{|c|}{ How often in the past 4 weeks did you: have trouble staying asleep (including waking up earlier than normal)? n (\%) } \\
\hline (0) Not at all & $735(29.4)$ & $388(28.6)$ & $164(34.8)$ & $183(27.1)$ \\
\hline (I) $1-3$ days & $684(27.3)$ & $375(27.6)$ & $144(30.6)$ & $165(24.4)$ \\
\hline (2) 4-7 days & $565(22.6)$ & $309(22.8)$ & $90(19.1)$ & $166(24.6)$ \\
\hline (3) $8-14$ days & $274(10.9)$ & $160(11.8)$ & $42(8.9)$ & $72(10.7)$ \\
\hline (4) $|5-2|$ days & $142(5.7)$ & $76(5.6)$ & $20(4.3)$ & $46(6.8)$ \\
\hline (5) $22-28$ days & $104(4.2)$ & $50(3.7)$ & II (2.3) & $43(6.4)$ \\
\hline Mean (SD) & $1.5(1.4)$ & $1.5(1.4)$ & $1.2(1.3)$ & $1.7(1.5)$ \\
\hline \multicolumn{5}{|c|}{ How often in the past 4 weeks did you: wake up after your usual amount of sleep feeling tired and worn out? n (\%) } \\
\hline (0) Not at all & $810(32.4)$ & $345(25.4)$ & $143(30.4)$ & $322(47.7)$ \\
\hline (I) I-3 days & $665(26.6)$ & $367(27.0)$ & $127(27.0)$ & |7| (25.3) \\
\hline (2) 4-7 days & $477(19.1)$ & $296(21.8)$ & $84(17.8)$ & $97(14.4)$ \\
\hline (3) $8-14$ days & $280(11.2)$ & $182(13.4)$ & $57(12.1)$ & $4 I(6 . I)$ \\
\hline (4) $|5-2|$ days & $178(7.1)$ & $104(7.7)$ & $46(9.8)$ & $28(4.2)$ \\
\hline (5) $22-28$ days & $94(3.8)$ & $64(4.7)$ & $14(3.0)$ & $16(2.4)$ \\
\hline Mean (SD) & $1.5(1.4)$ & $1.7(1.4)$ & I.5 (I.4) & $1.0(1.3)$ \\
\hline
\end{tabular}

Note: No patients included had missing JSEQ data.

Abbreviations: EU, European Union; JSEQ, Jenkins Sleep Evaluation Questionnaire; SD, standard deviation.

Table 5 EQ-5D-3L multivariate modeling showing logistic (perfect health versus non-perfect health patients) and linear (non-perfect health patients only) regression

\begin{tabular}{|c|c|c|c|}
\hline & 5EU & USA & China \\
\hline \multicolumn{4}{|c|}{ Logistic regression (perfect health versus non-perfect health patients) } \\
\hline \multicolumn{4}{|c|}{ JSEQ score } \\
\hline Number of observations & $\mathrm{I}, \mathrm{I} 36$ & 294 & 400 \\
\hline Odds ratio $(95 \% \mathrm{Cl})$ & $1.27(1.18,1.36)$ & $1.23(1.12,1.38)$ & $1.19(1.10,1.28)$ \\
\hline$P$-value & $<0.001$ & $<0.001$ & $<0.001$ \\
\hline \multicolumn{4}{|c|}{ Linear regression of JSEQ score (non-perfect health patients only) } \\
\hline \multicolumn{4}{|c|}{ With EQ-5D score } \\
\hline Number of observations & 923 & 276 & 270 \\
\hline Coefficient & 0.019 & 0.007 & 0.008 \\
\hline$P$-value & $<0.001$ & $<0.001$ & 0.055 \\
\hline \multicolumn{4}{|c|}{ With 7-item CAT score (excluding sleep item) } \\
\hline Number of observations & $\mathrm{I}, 098$ & 357 & 404 \\
\hline Coefficient & 0.695 & 0.725 & 0.224 \\
\hline$P$-value & $<0.001$ & $<0.001$ & 0.001 \\
\hline
\end{tabular}

Notes: Perfect health was defined as an EQ-5D-3L score of I and non-perfect health $<I$. For the logistic regression, an odds ratio of $>I$ represented the change in odds of a non-perfect health for a unit increase in JSEQ score. For the linear regression of JSEQ score with EQ-5D, a positive coefficient was associated with a patient with worse health status (lower EQ-5D score). A higher/lower value of the coefficient indicated a greater effect of the variable.

Abbreviations: CAT, COPD assessment test; Cl, confidence interval; COPD, chronic obstructive pulmonary disease; EQ-5D-3L, EuroQol five-dimension questionnaire; EU, European Union; JSEQ, Jenkins Sleep Evaluation Questionnaire. 
Table 6 Current treatment for COPD

\begin{tabular}{|c|c|c|c|c|}
\hline & Overall $(n=2,504)$ & $5 E U(n=I, 358)$ & USA $(n=47 I)$ & China $(n=675)$ \\
\hline \multicolumn{5}{|c|}{ Physician type responsible for treatment decisions, $n$ (\%) } \\
\hline Number of missing observations & II (0.4) & $4(0.3)$ & $7(1.5)$ & 0 \\
\hline PCP only & $799(32.0)$ & $584(43.1)$ & $215(46.3)$ & $\mathrm{n} / \mathrm{a}$ \\
\hline Specialist involvement ${ }^{\mathrm{a}}$ & $1,694(68.0)$ & $770(56.9)$ & $249(53.7)$ & $675(100)$ \\
\hline \multicolumn{5}{|l|}{ Current treatment regimen, ${ }^{\mathrm{b}} \mathrm{n}(\%)$} \\
\hline Number of missing observations & $5(0.2)$ & $2(0.1)$ & $2(0.4)$ & $I(0.1)$ \\
\hline Short-acting onlyc & $156(6.2)$ & $72(5.3)$ & $44(9.4)$ & $40(5.9)$ \\
\hline ICS & $116(4.6)$ & $22(1.6)$ & $10(2.1)$ & $84(12.5)$ \\
\hline LAMA & $335(13.4)$ & $253(18.7)$ & $76(16.2)$ & $6(0.9)$ \\
\hline LABA & $115(4.6)$ & $83(6.1)$ & $5(1.1)$ & $27(4.0)$ \\
\hline ICS + LABA (fixed or free) & $761(30.5)$ & $266(19.6)$ & $140(29.9)$ & $355(52.7)$ \\
\hline ICS + LAMA & $33(1.3)$ & $19(1.4)$ & $14(3.0)$ & 0 \\
\hline LAMA + LABA & $|5|(6.0)$ & $142(10.5)$ & $6(1.3)$ & $3(0.5)$ \\
\hline ICS + LAMA + LABA (fixed or free) & $618(24.7)$ & $457(33.7)$ & $150(32.0)$ & II (I.6) \\
\hline Other (no inhaled maintenance medication) & $214(8.6)$ & $42(3.1)$ & $24(5.1)$ & $148(22.0)$ \\
\hline \multicolumn{5}{|c|}{ Current treatment chosen by the physician for improvement in night-time symptom relief, $n(\%)$} \\
\hline Number of missing observations & $424(16.9)$ & $258(19.0)$ & $161(34.2)$ & $5(0.7)$ \\
\hline Not night-time symptom relief & $983(47.3)$ & $614(55.8)$ & $167(53.9)$ & $202(30.2)$ \\
\hline Night-time symptom relief & I,097 (52.7) & $486(44.2)$ & $143(46.1)$ & $468(69.9)$ \\
\hline \multicolumn{5}{|c|}{ Current COPD treatment chosen by the physician for improvement in daytime symptom relief, $n$ (\%) } \\
\hline Number of missing observations & $424(16.9)$ & $258(19.0)$ & $161(34.2)$ & $5(0.7)$ \\
\hline Not daytime symptom relief & $714(34.3)$ & $44 I(40.1)$ & $118(38.1)$ & $155(23.1)$ \\
\hline Daytime symptom relief & $1,366(65.7)$ & $659(59.9)$ & $192(61.9)$ & $515(76.9)$ \\
\hline
\end{tabular}

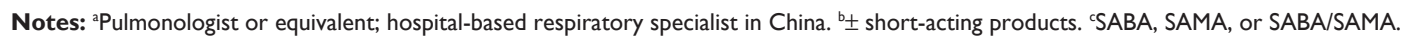

Abbreviations: COPD, chronic obstructive pulmonary disease; EU, European Union; ICS, inhaled corticosteroid; LABA, long-acting $\beta_{2}$-agonist; LAMA, long-acting muscarinic antagonist; $n / a$, not applicable; PCP, primary care physician; SABA, short-acting $\beta_{2}$-agonist; SAMA, short-acting muscarinic antagonist.

specialist (Table 6). The majority of patients were receiving maintenance treatment, with an inhaled corticosteroid/longacting $\beta_{2}$-agonist (LABA) combination accounting for $30.5 \%$ of current treatment regimens, triple therapy accounting for $24.7 \%$, and long-acting muscarinic antagonists (LAMAs) accounting for $13.4 \%$. LAMA/LABA combination therapy accounted for $6.0 \%$ of current treatment (Table 6). The relatively high "other" category among patients surveyed in China reflected high prescribing of xanthine that was not observed in Europe or the USA. Overall, in just over half $(52.7 \%)$ of patients, physicians stated that they made their treatment choice on the basis of night-time symptoms, with this proportion notably higher among the cohort from China (69.9\%; Table 6). Targeting daytime symptoms was cited as the reason for current treatment choice in $65.7 \%$ of patients, rising to $76.9 \%$ of patients in China.

\section{Discussion}

This study examined the effect of sleep disturbance on symptoms and health status among patients with COPD managed in a real-world treatment setting and surveyed as part of a respiratory DSP. Our findings show that the majority ( $\geq 66 \%$ ) of patients had at least some night-time symptoms and associated sleep disturbance over a monthly period, with $\geq 8 \%$ of patients experiencing night-time symptoms on a daily basis.

Quality of sleep was quantified using the validated JSEQ instrument, on which a mean score of 6.1 was recorded for our study population as a whole. However, it should be noted that JSEQ is not a COPD-specific instrument and other nonCOPD reasons may also have contributed to the sleep quality reported in this study. JSEQ scores were generally similar between the geographical regions tested, with the cohort from the USA showing a slightly lower score (5.4) than that from Europe or China, indicative of marginally better sleep quality. Previous research in a middle-aged population determined that a JSEQ score $\geq 3$ was sufficient to identify patients with frequent sleep complaints (indicative of sleep disturbance at least once a week during the previous month). ${ }^{16}$ Across JSEQ categories, the proportion of the total population surveyed in our study with a JSEQ score $\geq 3$ ranged from $20.6 \%$ to $23.6 \%$, with night-time awakening representing the most common characteristic of sleep disturbance. This may tie in with patient-reported psychological or functional scores, which were highest for "constant lack of energy" (42.7\%) and "tiredness through lack of sleep" (36.5\%). 
In our study, almost three-quarters of patients had experienced at least one JSEQ category of night-time sleep disturbance, as evidenced by a JSEQ score $>0$. Such problems included trouble falling asleep, waking up several times per night, trouble staying asleep, and feeling tired and worn out after having the usual amount of sleep. This figure is consistent with that reported in a previous COPD DSP survey in which $78 \%$ of patients with COPD in five European countries reported night-time disturbance (JSEQ score $>0$ within last 28 days). ${ }^{7}$ In both studies, sleep disturbance was accompanied by a relatively high frequency of night-time symptoms, with the frequency of symptoms likely to be underestimated, to varying degrees, if reported by the physician rather than the patient. Generally, however, our study found moderate-substantial rates of concordance between physician and patient reports of night-time symptoms. This level of agreement is perhaps surprising, given the apparent lack of physician awareness surrounding night-time symptoms that has been reported in the literature. ${ }^{2,9}$ It is possible that the "awareness" reported herein reflects the direct questioning of physicians about night-time symptoms, specifically. The proportion of physicians who prescribed medication with the alleviation of night-time symptoms in mind did not correlate with the purported high rate of symptom recognition.

In the overall population, current medication was prescribed for improvement in night-time symptom relief in only half of the patients $(52.7 \%)$. This rate was substantially higher in the cohort from China (69.9\%) and may be reflective of the country's health care system, where patient consultations typically occur in hospitals when patients are symptomatic and are more suggestive of emergency care than routine visits. Although the majority of the overall population was considered symptomatic ( $>91 \%$ of patients had CAT scores of $\geq 10$ ), patients from China demonstrated a higher symptom burden than other regions, as evidenced by almost all patients $(98.5 \%)$ showing a CAT score $\geq 10$, and this may have driven the need for medication for both night-time and daytime symptom relief.

That deficits in sleep quality persisted, even when emergence of night-time symptoms was recognized and medication given, is cause for concern. "Tiredness through lack of sleep" was reported in more than half $(58.3 \%)$ of patients surveyed in China, despite the acknowledged higher rates of targeted medication prescribing in this cohort versus the overall population. This may suggest that physicians generally lack clear understanding of the burden of night-time symptoms and are not prescribing the most appropriate medications. The possibility that physicians were knowingly prescribing medication for sleep disturbance that was unrelated to COPD cannot be discounted. By including confounding variables, we were able to determine with some confidence whether physicians chose treatment for night-time symptoms because of patients' complaints of sleep disturbance. However, we were unable to adjust for therapeutic effects, and results should, therefore, be interpreted with a certain degree of caution.

Regular disturbance of sleep, possibly as a result of the emergence of night-time COPD symptoms, is linked with deficits in sleep efficiency (the ratio of estimated total sleep time and total time spent in bed) and impaired sleep quality among patients with COPD. ${ }^{2,9,17}$ Sleep-quality deficits have been shown to affect the vast majority of patients with COPD, with rates in excess of $70 \%$ reported in the literature. ${ }^{18,19}$ If left unmanaged, evidence suggests that sleep deficiencies will gradually encroach upon daytime activities. Impaired sleep quality has been associated with low daytime energy levels, chronic fatigue, daytime sleepiness, and impairments in patient-reported QoL. ${ }^{2}$ It is likely of course that the cycle of interrupted sleep and daytime lethargy is self-perpetuating, with a retrospective analysis of sleep quality in patients with severe COPD identifying daytime hypoxemia as a predictor of sleep efficiency. ${ }^{17}$

We were able to demonstrate a strong and significant relationship between the increasing frequency of sleep disturbance according to JSEQ score, and worsening health status, as measured by the EQ-5D-3L. Such findings are in broad agreement with previous studies, which have linked sleep disturbance, and poor sleep quality in particular, with deficits in the QoL of patients with COPD of varying severity., $518-22$ There is some evidence to directly link the severity of COPD disease progression with sleep quality and, ultimately, QoL or health status. ${ }^{20}$

The CAT has been used previously to show the impact of COPD on health status in the context of night-time or early-morning symptoms in a cross-sectional survey of 1,239 patients with COPD, identified using US medical and pharmacy claims data. ${ }^{5}$ The emergence of either symptom type was significantly associated with poorer health status (in terms of CAT score). In our study, we used a modified version of the CAT, in which the original sleep component was excluded, as a measurement for COPD symptoms. The CAT scores indicated that the majority $(>91 \%)$ of the population were symptomatic (CAT score $\geq 10$ ). Regression analyses showed a significant association between JSEQ score and 7-item CAT score, indicating that increasing sleep 
disturbance had a significant impact on COPD symptoms. However, it could be argued that the reverse is also true, with progressively more symptomatic patients being associated with an increasing number of sleep complaints. ${ }^{17}$

The findings from this study should be interpreted in light of certain limitations. The most recent mean postbronchodilator $\mathrm{FEV}_{1}$ for the whole population $(62.9 \%$ of predicted) was in the range associated with moderate airflow limitation $\left(50 \% \leq \mathrm{FEV}_{1}<80 \%\right.$ predicted) and therefore it may be less likely that these patients will have sleep-related issues. ${ }^{11}$ However, spirometry data were missing for $59.7 \%$ of patients. The survey also included only those patients who were consulting their physician and, as such, the generalizability of the findings to the COPD population as a whole is unknown. Furthermore, our study enrolled patients presenting within both primary and specialist care settings and was not designed to evaluate potential differences in night-time symptoms and sleep disturbance between these two groups. Given the reasonable assumption that patients managed under specialist care were more severely affected by COPD, higher rates of sleep disturbance may perhaps have been anticipated among these patients.

The quality of our data was reliant on accurate reporting of information by physicians and patients. The prospective consecutive sampling approach was designed to limit patient selection bias. However, its success was highly dependent on the integrity of the participating physician and adherence to this instruction could not be verified. In addition, for many patients treatment decisions were made by primary care physicians rather than respiratory specialists, which may have affected outcomes.

Conducted in a real-world setting and covering a broad geographical area, our study revealed the widespread occurrence of night-time symptoms and sleep disturbance in patients with COPD. Importantly, disrupted sleep was associated with the worsening of both symptoms and health status, serving to underline the importance of an effective management strategy that directly addresses sleep disturbances. While physicians may acknowledge that the majority of patients with COPD experience night-time respiratory symptoms ( $\geq 66 \%$ over a 4 -week period), this doesn't always appear to translate into disease-management practice, given that only $53 \%$ of patients currently receive medication specifically targeting night-time symptomatology. This research provides further evidence of the need to address night-time symptoms and associated sleep disturbances (in addition to the detrimental daytime symptoms of dyspnea and breathlessness) in order to bring about improvements in patients' QoL.

\section{Conclusion}

Night-time COPD symptoms and sleep disturbance are common among patients with COPD, and sleep disturbance has a detrimental impact on symptoms, health status, and QoL. The burden of COPD night-time symptoms needs to be considered relative to that of COPD daytime symptoms in order to fully understand its impact on patients' lives. This study shows that despite physicians acknowledging that most patients with COPD experience night-time symptoms, this does not appear to translate into disease management practice and highlights the clinical need to address night-time symptoms with tailored treatment approaches.

\section{Acknowledgments}

This study was supported by AstraZeneca. Medical writing support was provided by Caroline Shepherd and Thomas Owens of Complete Medical Communications, funded by AstraZeneca.

The authors wish to thank Stuart Blackburn, a senior statistician and employee of Adelphi Real World, who provided analytical support.

\section{Author contributions}

All authors contributed to conception and design of the study/ analyses. MS carried out data and statistical analyses and data acquisition. All authors participated in data interpretation and manuscript drafting, reviewing, and development.

\section{Disclosure}

Ulf Holmgren, Gina Bergström, and Bo Ding are employees of AstraZeneca. Mark Small is an employee of Adelphi Real World. The authors report no other conflicts of interest in this work.

\section{References}

1. Zamarron C, Garcia PV, Morete E, del Campo MF. Association of chronic obstructive pulmonary disease and obstructive sleep apnea consequences. Int J Chron Obstruct Pulmon Dis. 2008;3(4):671-682.

2. McNicholas WT, Verbraecken J, Marin JM. Sleep disorders in COPD: the forgotten dimension. Eur Respir Rev. 2013;22(129):365-375.

3. Cormick W, Olson LG, Hensley MJ, Saunders NA. Nocturnal hypoxaemia and quality of sleep in patients with chronic obstructive lung disease. Thorax. 1986;41(11):846-854.

4. Krachman S, Minai OA, Scharf SM. Sleep abnormalities and treatment in emphysema. Proc Am Thorac Soc. 2008;5(4):536-542.

5. Stephenson JJ, Cai Q, Mocarski M, Tan H, Doshi JA, Sullivan SD. Impact and factors associated with nighttime and early morning symptoms among patients with chronic obstructive pulmonary disease. Int $J$ Chron Obstruct Pulmon Dis. 2015;10:577-586.

6. Budhiraja R, Siddiqi TA, Quan SF. Sleep disorders in chronic obstructive pulmonary disease: etiology, impact, and management. J Clin Sleep Med. 2015;11(3):259-270.

7. Price D, Small M, Milligan G, Higgins V, Gil EG, Estruch J. Impact of night-time symptoms in COPD: a real-world study in five European countries. Int J Chron Obstruct Pulmon Dis. 2013;8:595-603. 
8. Breslin E, van der SC, Breukink S, et al. Perception of fatigue and quality of life in patients with COPD. Chest. 1998;114(4):958-964.

9. Agusti A, Hedner J, Marin JM, Barbe F, Cazzola M, Rennard S. Nighttime symptoms: a forgotten dimension of COPD. Eur Respir Rev. 2011; 20(121):183-194.

10. Phillips BA, Cooper KR, Burke TV. The effect of sleep loss on breathing in chronic obstructive pulmonary disease. Chest. 1987;91(1):29-32.

11. Global Initiative for Chronic Obstructive Lung Disease. Global Strategy for the Diagnosis, Management and Prevention of COPD, Global Initiative for Chronic Obstructive Lung Diseases (GOLD); 2016 [updated 2016] Available from: http://www.goldcopd.org. Accessed June 16, 2016.

12. Jenkins CD, Stanton BA, Niemcryk SJ, Rose RM. A scale for the estimation of sleep problems in clinical research. J Clin Epidemiol. 1988; 41(4):313-321.

13. Anderson P, Benford M, Harris N, Karavali M, Piercy J. Real-world physician and patient behaviour across countries: Disease-Specific Programmes - a means to understand. Curr Med Res Opin. 2008; 24(11):3063-3072.

14. Rabin R, de CF. EQ-5D: a measure of health status from the EuroQol Group. Ann Med. 2001;33(5):337-343.

15. Cohen J. Weighted kappa: nominal scale agreement with provision for scaled disagreement or partial credit. Psychol Bull. 1968;70(4): 213-220.
16. Lallukka T, Rahkonen O, Lahelma E, Arber S. Sleep complaints in middle-aged women and men: the contribution of working conditions and work-family conflicts. J Sleep Res. 2010;19(3):466-477.

17. McSharry DG, Ryan S, Calverley P, Edwards JC, McNicholas WT. Sleep quality in chronic obstructive pulmonary disease. Respirology. 2012;17(7):1119-1124.

18. Nunes DM, Mota RM, de Pontes Neto OL, Pereira ED, de Bruin VM, de Bruin PF. Impaired sleep reduces quality of life in chronic obstructive pulmonary disease. Lung. 2009;187(3):159-163.

19. Scharf SM, Maimon N, Simon-Tuval T, Bernhard-Scharf BJ, Reuveni H, Tarasiuk A. Sleep quality predicts quality of life in chronic obstructive pulmonary disease. Int J Chron Obstruct Pulmon Dis. 2010;6:1-12.

20. Dignani L, Toccaceli A, Lucertini C, Petrucci C, Lancia L. Sleep and quality of life in people with COPD: a descriptive-correlational study. Clin Nurs Res. 2015;25(4):432-447.

21. Soler-Cataluna JJ, Sauleda J, Valdes L, et al. [Prevalence and perception of 24-hour symptom patterns in patients with stable chronic obstructive pulmonary disease in Spain]. Arch Bronconeumol. 2016;52(6): 308-316. Spanish.

22. Hynninen MJ, Pallesen S, Nordhus IH. Factors affecting health status in COPD patients with co-morbid anxiety or depression. Int $J$ Chron Obstruct Pulmon Dis. 2007;2(3):323-328.
International Journal of COPD

\section{Publish your work in this journal}

The International Journal of COPD is an international, peer-reviewed journal of therapeutics and pharmacology focusing on concise rapid reporting of clinical studies and reviews in COPD. Special focus is given to the pathophysiological processes underlying the disease, intervention programs, patient focused education, and self management protocols.

\section{Dovepress}

This journal is indexed on PubMed Central, MedLine and CAS. The manuscript management system is completely online and includes a very quick and fair peer-review system, which is all easy to use. Visit http://www.dovepress.com/testimonials.php to read real quotes from published authors.

Submit your manuscript here: http://www.dovepress.com/international-journal-of-chronic-obstructive-pulmonary-disease-journal 